16 a 18 de outubro de 2019 - Campinas | Brasil

\title{
"Expressão de ABHD5 em tecido adiposo no envelhecimento e a influência do exercício físico em sua atividade"
}

Rafael dos Santos Brícola', André V. Cordeiro, Renata R. Braga, Bárbara Crisol, Lucas Barbosa,Vagner R. Silva, Diego Melo, Dennys Cintra, Leandro Pereira, José Rodrigo Pauli, Eduardo R. Ropelle1 .

\section{Resumo}

A lipólise é um mecanismo biológico complexo responsável por promover a degradação de moléculas de gordura para obtenção de substrato energético. O processo de envelhecimento é acompanhado pelo aumento do acúmulo de tecido adiposo, que ocorre ao menos em parte, devido a redução da capacidade de ativação da lipólise. Por outro lado, sabidamente o exercício físico é reconhecido como um potente estimulador do processo da lipólise. Recentemente, a proteína ABHD5 (do inglês, $\alpha-\beta$ hidrolase domain-contain protein 5 ) foi descrita como molécula chave no controle da lipólise, ao passo que a interação entre a ABHD5/ATGL é determinante para a metabolização de triglicerídeos para obtenção de energia. Contudo pouco se conhece sobre a influência do envelhecimento e do exercício físico sobre a expressão/atividade da ABHD5. Portanto o atual projeto pretende avaliar o efeito do envelhecimento sobre o conteúdo proteico de ABHD5 no tecido adiposo de camundongos, bem como investigar o papel do exercício físico sobre a ABHD5 e a ativação da lipólise em camundongos idosos. A realização do presente projeto poderá ajudar a elucidar o papel da ABHD5 sobre o acúmulo de gordura durante o envelhecimento, bem como determinar a possível capacidade do exercício físico em modular a atividade da ABHD5 e da lipólise no envelhecimento.

Palavras-chave: Lipólise; Exercicio Físico; Envelhecimento.

\section{Introdução}

A deficiência na indução do processo de lipólise contribui de maneira significativa para 0 acumulo excessivo de gordura corporal, em especial em indivíduos idosos ${ }^{1}$. Por outro lado, o exercício físico é considerado um potente indutor fisiológico do processo de lipólise, contribuindo para redução da adiposidade ou ainda a manutenção do fenótipo magro. Recentemente foi descrito que a ativação da proteína ABHD5 é uma resposta molecular de extrema importância para a manutenção e disponibilidade energética do organismo, exercendo função primordial para a ativação da via da lipólise ${ }^{2}$, como representado na figura a seguir:

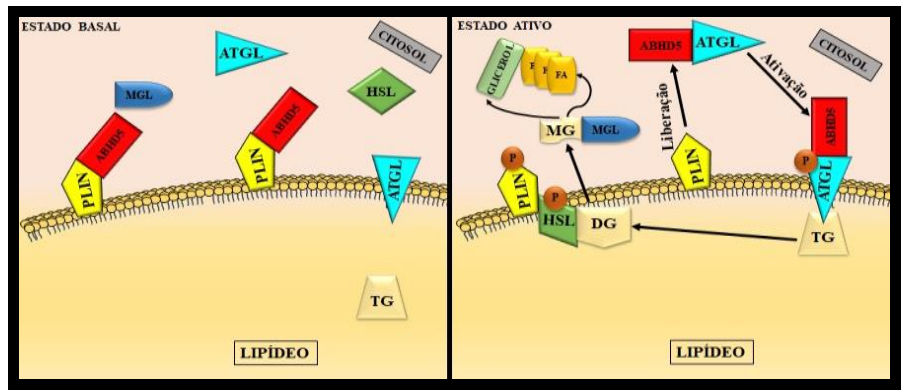

Figura 1. Lipólise: EM ESTADO BASAL: ABHD5 encontra-se ligada a perilipina, inibindo a ação de ATGL. HSL também não possui expressão de atividade por não estar fosforilada. EM ESTADO ATIVO: Quando fosforilada, ABHD5 tem sua liberação no citosol, onde possui afinidade com ATGL e rapidamente se ligam, fosforilando ATGL e dando início a ação sobre os triglicerídeos. Após ação de ATGL o triglicerídeo é reduzido a diglicerídeo, então HSL se transloca para a membrana, ligando-se a perilipina, onde realiza a quebra de diglicerídeo em monoglicerídeo, após, MGL o quebra, liberando glicerol e três ácidos graxos livres.

\section{Resultados e Discussão}

Os resultados apresentados na figura a seguir demonstram redução da fosforilação da proteína
Perilipína e o conteúdo da proteína HSL no tecido subcutâneo em modelo experimental de envelhecimento.
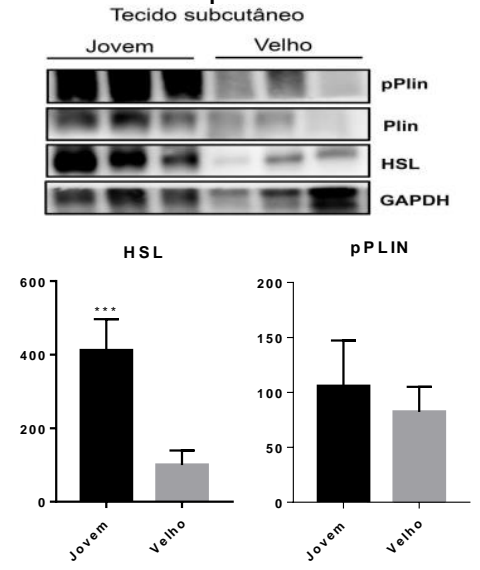

Figura 2 - "Quantificação da proteína Perilipina Fosforilada em tecido adiposo subcutâneo". (B) - $A$ expressão de Perilipina fosforilada não foi significativamente diferente entre os grupos

Velho controle vs jovem ( $n=3)$. Figura $2 C$ - "Quantificação da proteína HSL em tecido adiposo subcutâneo" (C) - Foi encontrada diferença significativa na expressão de HSL no grupo Jovem em relação ao grupo Velho controle***, jovem vs. Velho, $p<0,001$.

\section{Conclusões}

Os resultados, obtidos até o momento, evidenciam que o envelhecimento de fato reduz a capacidade lipolítica no tecido adiposo, como confirmado através de dois marcadores de lipólise.

Um novo experimento está sendo realizado para avaliar a expressão de ABHD5 no tecido adiposo de animais velhos em repouso e após o exercício físico.

\section{Agradecimentos}

\section{TFAPESP}

1 - BARZILAI N, RENNERT G. The Rationale for Delaying Aging and the Prevention of Age-Related Diseas es. Rambam Maimonides Med $J$ DOI:10.5041/RMMJ.10087, 2012.

2 - Sanders, M. A. et al. Endogenous and Synthetic ABHD5 Ligands Regulate ABHD5-Perilipin Interactions and Lipolysis in Fat and Muscle. Cell Metab 22, 851 860 